\title{
O ENIGMA DO CAPITAL E AS CRISES DO CAPITALISMO
}

Elizardo Costa

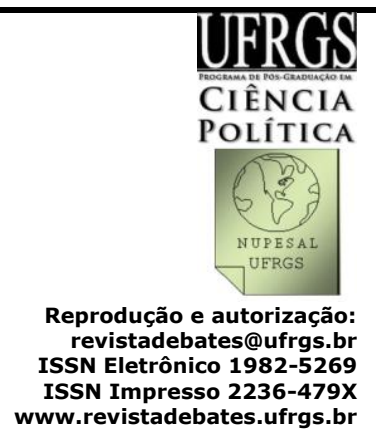

HARVEY, David. O Enigma do capital e as crises do capitalismo. Lisboa: Ed Bizâncio, 2011. 336 p.

David Harvey é professor de geografia da universidade de Nova Iorque. Suas pesquisas são orientadas para os estudos sobre as áreas de geografia urbana e da globalização. Autor de diversos livros de muita influência nas áreas das ciências humanas e sociais, Harvey vem publicando desde os anos 1960, destacando-se Explanation in Geography de 1969, Social Justice and the City na década de 1970, e por fim, no auge da sua vida acadêmica publica nos anos 1990 a obra A Condição Pós-moderna, muito conhecida no Brasil, onde ele afirma que a globalização econômica, cultural e política em curso disponibilizou novas imagens e identidades no mundo global, e que ocorreu uma intensificação na forma de se fazer comunicação em todo o planeta - esse fator, é outro elemento sociológico a ser considerado nessa atual configuração social que estamos inseridos. A compressão entre 0 Tempo e 0 Espaço também alteraram-se consideravelmente, e a obra resenhada é de certa forma uma continuação desse raciocíno, mas agora com uma forte inspiração marxiana dos aspectos econômicos globalizados pelo capital.

Neste sentido, Harvey descreve de maneira detalhada a atual crise econômica que teve início com o subprime imobiliário de 2008, nos Estados Unidos, que posteriormente colocou quase todos os segmentos da economia americana em grandes dificuldades de liquidez. A crise no coração do principal país capitalista do mundo alastrou-se rapidamente para outros países, principalmente a Europa. Debruçando-se sobre a possibilidade de sairmos, ou não, dessa nova crise cíclica, mas que não difere das crises sistêmicas passadas, ele afirma que, como nunca, a solução passa pelo equilíbrio de forças das classes sociais. E depende em largamente medida, da capacidade de resposta das massas em erguerem-se e afirmarem que esse modelo de organização societal está esgotado. Harvey defende que o capitalismo não 
pode resolver os problemas gerados pela crise, porque não pode superar as suas próprias contradições.

No primeiro capítulo, Harvey enuncia as condições necessárias para a acumulação do capital dentro do processo de globalização que foi facilitado pela reorganização radical dos sistemas de transportes e comunicacionais, que reduziram consideravelmente os custos dos movimentos das mercadorias, e que possibilitavam a organização rigorosa da produção em cadeia em todo espaço global. Em outras palavras, essa reorganização gerou também, as crises de reprodução do capitalismo e os riscos sistêmicos de longo prazo que o capital representa nos últimos 30 anos. Assim a perturbação encontra-se focada nos riscos sistêmicos inerentes ao capitalismo de livre mercado que os economistas não foram capazes de compreender quando nasceu a crise, e até hoje parecem não terem ideias de como enfrentá-la. Por outro lado, essa crise apesar das suas proporções e tamanho não se difere de crises cíclicas passadas. O que ocorreu agora é que se assistiu "a uma reconfiguração espetacular da geografia da produção e da localização do poder político econômico" (HARVEY, 2011, p. 40).

No segundo capítulo, o autor descreve de forma didática o surgimento da burguesia mercantil e industrial, bem como, a ascensão inicial do capitalismo financeiro através da monetarização da gestão do "nexo entre o Estado e as finanças" - mesmo que cada Estado tenha as suas características próprias de organização financeira. Por meio da construção analítica de cada conceito, ele torna a leitura gradativamente mais complexa na medida em que uma maior articulação é necessária para explicar a dinâmica do fluxo do capital e seus caminhos sinuosos na sua estranha lógica de comportamento, acreditando ser essa a tarefa fundamental para explicar as condições em que vivemos atualmente.

O aprofundamento das crises cíclicas aumentou consideravelmente a partir da década de 70 do século passado. Após esse momento, o mundo passou a ser governado pela ditadura dos bancos centrais, que são instrumentalizados pelos mercados. As bases teóricas e ideológicas para essa ordem financeira já haviam sido estabelecidas em Breton Woods, em 1944, onde foram criados os poderes necessários para a arquitetura financeira internacional. Ao mesmo tempo, no seio dos movimentos sociais nesse momento, surgem os primeiros focos de resistência contra o papel disciplinar, neocolonialista e imperialista colocado pelo FMI, OMC e Banco Mundial.

No terceiro capítulo, Harvey analisa a acumulação perpétua do capital. Inspirado pela perspectiva marxiana sobre a relação entre o capital e a disponibilidade das reservas acessíveis e suficientes de força de trabalho, conceito que Marx caracterizou como sendo "o exército industrial de reserva", Harvey afirma que essa é a condição necessária para a reprodução e para a expansão do capital. Portanto, esse exército de reserva precisa ser acessível, socializado, disciplinado, flexível e dócil (HARVEY, 2011). Hoje, as mulheres constituem a espinha dorsal do trabalho flexível e precário, sendo por isso, essencial a sua mão de obra, e inserem-se dentro da lógica tripartida da 
constituição do trabalho global, a capacidade que os capitalistas possuem em mobilizar as matérias-primas, os equipamentos e a força de trabalho. $O$ Estado como arquiteto jurídico das leis trabalhistas e das condições de trabalho é o provedor de uma infraestrutura social - educação, saúde e formação - com objetivo de manter vivo o exército de reserva.

Assim, os capitalistas incrementaram as inovações tecnológicas e organizacionais, como também, incentivam a concorrência entre os trabalhadores (por isso, a persistência de diferenças salariais entre homens e mulheres, por exemplo) com vista à obtenção de uma maior rentabilidade no trabalho, e redução dos custos de produção. Nessas circunstâncias, surgem as lutas sociais e sindicais, que possuem maior ou menor força de acordo com o país e o contexto histórico de organização do trabalho. Portanto,

[...] as crises são racionalizadores irracionais de um capitalismo sempre instável, que vem gerando graves desastres ambientais e humanos na maximização das relações entre o capital e o trabalho, que são mediadas pelas escolhas tecnológicas, e pelas formas organizacionais (HARVEY, 2011, p. 86).

Além disso, as revoluções tecnológicas engendradas pelo capitalismo são uma "faca de dois gumes". São tanto perturbadoras e destrutivas, como evolutivas e criativas. As inovações tecnológicas e financeiras desestabilizam, mas também abrem os caminhos para absorção dos excedentes de capitais, causando a chamada "destruição criativa", conceito que Harvey recupera de Joseph Schumpeter. Por outro lado, aqui é preciso frisar que as dimensões da luta de classes também merecem ser consideradas. As oposições de base, incluindo a sabotagem de novas tecnologias, e das formas organizacionais pelos trabalhadores, possuem uma longa história e ainda são muito utilizadas nos tempos atuais.

No quinto capítulo, Harvey ainda foca sua análise sobre o desenvolvimento do capital desde a revolução inglesa, demonstrando com alguns exemplos concretos como a saga do capitalismo é repleta de paradoxos - crises econômicas, guerras, degradação ambiental, aumento da pobreza, múltiplas alienações, insegurança, violência. Mas, ainda consegue recuperar alguns aspectos positivos do capitalismo de forma irônica, como por exemplo, há pessoas que vivem num mundo onde os níveis de vida são elevados; a revolução comunicacional; interação humana; os progressos médicos; e o aumento da expectativa de vida. Portanto, o caráter revolucionário do capitalismo consiste na sua evolução dentro dos processos de relações contraditórias. Pois, ao mesmo tempo em que os capitalistas mobilizam as novas tecnologias e as formas organizacionais contra a força de trabalho, essa fenômeno vai ao sentido de promover a acumulação interminável de lucros. Essa concepção tem desempenhado um papel crucial na evolução do capitalismo, o que ele chama de "concepção mental do mundo" (HARVEY, 2011, p. 139). 
Por conseguinte, o fetiche da tecnologia ocupa um lugar indevidamente proeminente na história burguesa, definindo tanto os seus efeitos espantosos, como as suas catástrofes. Na prática, o capitalismo parece ter evoluído em direção ao "equilíbrio pontuado" de Stephany Gould: período de evolução relativamente lento, mas razoavelmente harmoniosa entre as esferas sociais e pontuados por fases de perturbações e de reforma radical.

No capítulo seis, o autor faz uma caracterização geográfica da crise e mostra a superação do capital, que antes era limitado pela geografia nacional, e consecutivamente, superando essa barreira para obter maior acumulação, como já prevista por Marx. Por outro lado, a paisagem geográfica é moldada por uma tensão perpétua entre as economias de centralização e os lucros potencialmente elevados decorrentes da descentralização e da dispersão das crises cíclicas. Assim, Harvey afirma que as crises geograficamente localizadas têm sido endérmicas ao longo da história do capitalismo. Portanto, a "destruição criativa" na terra, desenvolvida pelo autor no capítulo sete, passa pela criação e recriação constante das relações espaciais para as interações humanas, que é uma das façanhas mais notórias no sistema capitalista. Sendo assim, a criação das formas territoriais de organização social, de construções locais, foi fundamental para a transformação da natureza pela humanidade. Enfim, tendo em vista à ação coletiva, pessoas e organizações juntam-se a fim de formarem associações territoriais que procurem gerir espaços sobre sua égide ao longo da história.

Portanto, em tempos de crise a irracionalidade do capitalismo evidencia-se. O capital excedentário, e a força de trabalho polarizam-se. Isso gera os mais diversos problemas sociais devido à lógica da mentalidade pela acumulação ilimitada dos capitalistas. Por conseguinte, questionar o futuro do próprio capitalismo enquanto sistema social parece ser adequado, e deve ocupar o primeiro plano do debate atual. $\mathrm{Na}$ maior parte do mundo capitalista, hoje, tem-se vivido um espantoso período em que as políticas têm sido despolitizadas e mercadorizadas, e a possibilidade de se definir um alcance racional, uma alternativa à (ir)racionalidade capitalista, é vital para perpetuação humana na terra.

Segundo Harvey, o problema central reside no fato de, no conjunto, não existir um movimento anticapitalista global suficientemente unificado, que seja capaz de enfrentar adequadamente a reprodução da classe capitalista e a perpetuação do seu poder no palco mundial. É preciso ter como norte que é impossível uma acumulação para sempre, e as perturbações que têm afetado o mundo nos últimos trinta anos. Harvey termina afirmando que o capitalismo nunca cairá por si, terá que ser empurrado. E assim sendo, a classe capitalista nunca abdicará do seu poder político e econômico. A crise é empurrada de um setor para o outro: primeiro é gerada pelo setor financeiro, depois é alargada para o Estado e, por conseguinte, transferida para os trabalhadores. Assim, a história das crises cíclicas do capitalismo consiste em transferir as causas da crise para outros setores da economia, incluindo aqui a 
questão do espaço geográfico: começando em um país, depois passa para um continente, e assim por diante.

Concluímos que se trata de uma obra que possui um olhar particular no que tange os atuais aspectos da globalização e da crise econômica em curso. Talvez, a principal restrição que o livro possa ter, seja no sentido de que $o$ autor não vislumbre muitas alternativas para se superar a atual crise econômica (foca-se mais em descrever a crise), principalmente na zona Euro, pois, como dissemos anteriormente, o autor utiliza alguns conceitos chaves que ele já havia utilizado no seu livro $A$ condição pós-moderna. Além disso, o livro pode polarizar com algumas concepções ideológico-epistemológicas no seio acadêmico, devido a Harvey ter um forte apego à saída marxiana da crise. O livro poderá vir a ser considerado anacrônico e já superado no tempo e no espaço. Por outro lado, o autor é fiel ao descrever de maneira simples, mas muito consistente as facetas do capitalismo global financeirizado e os seus impactos sobre a atual arquitetura global dos nossos tempos.

Elizardo Costa é Graduado em Ciências Sociais pela Universidade Federal do Espírito Santo (UFES). Mestre em Sociologia pela Faculdade de Economia da Universidade de Coimbra (FEUC), Portugal, e mestre em Sociologia pela École des Hautes Etudes en Sciences Sociales (EHESS) em Paris, França. Atualmente é doutorando no Centro de Estudos Sociais (CES) da Universidade de Coimbra (UC) Portugal, no Doutorado de Relações de Trabalho, Desigualdades Sociais, e Sindicalismo (Sociologia).

E-mail: eliascarpati@hotmail.com

Texto recebido em 17/07/2012. Aprovado em 05/11/2012. 